\title{
Fusion's turn again?
}

\section{Washington \& London}

AN old rule of thumb among US fusion researchers holds that the funding for the field almost always parallels the average price of oil, delayed by about a year. Although the current budget crisis may put that rule to the test, signs are emerging that political support for fusion research in the United States and Europe is strengthening again as oil prices rise.

This week, two reports from US panels will join a just-released study from the European Communities (EC) in setting priorities for fusion research in the coming decades. Representatives from Japan, the EC and the United States will discuss the new findings at a meeting in Washington later this month.

One US panel - a Department of Energy (DOE) independent advisory body led by $\mathrm{H}$. Guyford Stever - will recommend that DOE set goals of a demonstration fusion power plant by 2025 and an operating commercial plan by 2040. The panel will also advise DOE to participate in the $\$ 1,000$ million second stage of the International Thermonuclear Experimental Reactor (ITER), a longterm tokamak experiment that the United States, the Soviet Union, the EC and Japan are now planning, and request funds next year to begin construction of the US Compact Ignition Tokamak (CIT) at Princeton Plasma Physics Laboratory. If approved, CIT could be finished five years before ITER and would provide a solid physics foundation for the international project.

Next week, the US National Academy of Sciences is expected to recommend that the \$170-million-per-year US laser fusion programme should concentrate on upgrading existing facilities before starting a major demonstration facility. The report is likely to endorse spending $\$ 300$ million on the NOVA laser at the Lawrence Livermore National Laboratory, in order to raise its energy from about 100 kilojoules to 1 megajoule. That should be enough to reach break-even, although it will still provide only a tenth of the power needed for energy production. Plans for a reactor - known as the Laboratory Microfusion Facility - that could demonstrate energy-production techniques should be scrapped until early in the next century, the panel will conclude.

An independent panel of prominent European scientists and industrialists, chaired by Professor Umberto Colombo, from ENEA (the Italian energy research organization) has recommended that the EC extend the life of the current Joint European Torus (JET) reactor from 1992 until 1996. At its peak performance, JET is less than a factor of two away from break-even. But this can be maintained only for seconds, after which impurities from the reactor walls begin to contaminate the plasma. Keeping JET running until 1996 could solve the problem, says Charles Maisonnier, director of the EC fusion programme. Ministers from EC states are not expected to reach a decision on JET's future before early next year, but Maisonnier has "strong hopes" that the extended project will win approval.

The EC report also says that Europe should retain the capacity to go ahead with a solely European proposal, the Next European Torus (NET), in case there are problems with the international collaboration. NET would cost the EC about $\$ 3,900$ million, compared with a share of the estimated $\$ 4,900$ million cost of ITER. Despite the uncertainties, the report recommends that the EC participate in the second phase of ITER planning as the 'next step' in the EC's fusion programme. ITER would serve as an experimental intermediate between JET and a demon-

\section{UK NUCLEAR POWER}

\section{Third Hinkley reactor in limbo}

\section{London}

UK ENERGY Secretary John Wakeham has given planning permission for a pressurized water reactor (PWR) at Hinkley Point in Somerset. But Nuclear Electric, the new state-owned generating company, must wait until 1994 before the government decides whether to pay for the plant.

The proposed Hinkley C PWR was the subject of a long-running public inquiry, which closed last December. Wakeham has accepted the recommendationof the inquiry chairman Michael Barnes, to grant consent for the plant, outlined in a report released last week.

Barnes concluded that the PWR's benefits - increasing the diversity of Britain's electricity supply while cutting carbon dioxide and sulphur dioxide emissions - will "substantially outweigh" local environment and health risks, and high cost estimates for PWR-generated electricity.

Spiralling estimates of the cost of nuclear electricity forced the Department of Energy to remove nuclear stations from the plan to sell the electricity industry into the private sector, and to put the expansion of the nuclear programme on hold pending a review in 1994. The cost of nuclear power, relative to other sources, will be an important factor in the decision on Hinkley C. Despite the uncertainties, Nuclear Electric chairman John Collier welcomed last week's decision, saying: "Our job is to make sure the 1994 review has a favourable outcome". PeterAldhous stration electricity-generating reactor.

The first three-year conceptual design phase of the ITER programme has been based at the Max Plank Institute in Garching, West Germany, and is now nearing completion. All the international partners are expected to make a bid to host the second phase in their own geographic areas, on the assumption that it will give them an advantage when the time comes to pick a site for the facility itself.

But ITER's future remains uncertain: the thorny issue of intellectual property rights has not been fully worked out, and there is concern that the crumbling Soviet economy will not be able to meet its share of the costs. The UK Department of Energy is deferring its decision until the Colombo report has been studied in detail. Similarly, a decision by the US Department of Energy has been in abeyance, awaiting the report by the Stever committee. Even though ITER's second phase involves no construction, members will be expected to contribute as much as $\$ 50 \mathrm{mil}$ lion a year to its design.

Christopher Anderson \& Peter Aldhous BROADCASTING

\section{Satellite television faces a break}

\section{Tokyo}

THE two million or so Japanese who have bought expensive antennas and tuners to receive satellite television broadcasts are left this week wondering if they will soon have only blank screens to watch. Japan's only broadcasting satellite, Yuri-2b (Lily$2 b$ ), will run out of the fuel necessary to maintain geostationary orbit in a few months and a replacement satellite, Yuri$3 \mathrm{a}$, is seriously short of power.

Yuri-3a was launched successfully last week by the National Space Development Agency (NASDA), but is limping along on only 75 per cent of expected power because of a defect in the distribution circuit connected to the satellite's two solar panels. As a result, full television transmissions can be maintained for only two years "at best" instead of the seven years originally planned, according to Katsuo Yonezawa of NASDA's international affairs division. After that, one of the satellite's three transponders will have to be shut off and the national broadcasting corporation will lose one of its two channels. The second transponder will feed a new commercial channel.

The satellite failure comes on top of the loss of NHK's second broadcasting satellite, BS-2X, which was destroyed when a European Ariane rocket exploded. Yuri3a will now be alone until next April at the earliest when NHK hopes to launch satellite BS-3H aboard a US Titan rocket to replace the lost BS-2X. David Swinbanks 